\title{
Comparative Study On Seismic Responses Of Multistorey Building Frame With Infills Using Linear And Nonlinear Analysis
}

\author{
S.Swapna, T.Venkatesh, V.Kavitha, K.Sanjay Kumar
}

\begin{abstract}
In coming up with of RCC frames typically the result of infill walls is neglected however this wall contributes to the rigidity and firmness of the structure. within the gift study we'll compare the unstable responses of a building by coming up with a infill wall with the assistance of equivalent diagonal strut methodology victimisation linear and non linear analysis additionally victimisation E-tabs code
\end{abstract}

Keywords: Linear Analysis, Non-linear Analysis, Equivalent Diagonal Strut, unstable Responses.

\section{INTRODUCTION}

In the approach of linear analysis a structure is capable of returning to its original position even once the removal of load since the fabric has unyielding properties and there won't be a lot of amendment within the firmness of the structure and loading pattern. during this methodology the unknowns area unit determined the by framing the equations of equilibrium.

In non linear analysis the structure doesn't regain its original position once application of masses as a result there'll be amendment in form of the structure which ends up in giant displacements and rotation. This stretching results in a non linear relationship between the strain and therefore the displacement

\section{LITERATURE REVIEW}

Many authors within the past 20 years have done analysis on infill result on unstable parameters.

Wakchaure M.R, Ped S.P [1] studied the causes of masonry walls on high rise building is studied. Linear dynamic analysis on high rise building with the varied arrangements has been dole out. For, the analysis of high rise R.C.C framed building is modelled. Earthquake time history is performed. The analysis showed that thought of infill walls reduced the lateral shift and will increase the time and base shear thence it's essential to think about infill wall for analysis

Revised Manuscript Received on April 19, 2019.

S.Swapna, Assistant Professor, Department of Civil Engineering, Siddhartha Institute of Technology and Sciences, Hyderabad, Telangana, India.

T.Venkatesh, Assistant Professor, Department of Civil Engineering, Siddhartha Institute of Technology and Sciences, Hyderabad, Telangana, India.

V.Kavitha, Assistant Professor, Department of Civil Engineering, Siddhartha Institute of Technology and Sciences, Hyderabad, Telangana, India.

K.Sanjay Kumar, Assistant Professor, Department of Civil Engineering, Siddhartha Institute of Technology and Sciences, Hyderabad, Telangana, India.
Prof. P. B. Kulkarni, Nikhil.S. Agarwal [2] tried to guage the performance of RCC structures with infill wall and linear static analysis was performed by considering unstable unstable zone into consideration with varied percentages victimisation STAAD code. The results obtained from this observation showed that there's decrease in lateral displacement with increase in time and base shear.

Hemant B. Kaushik, Durgesh C. Rai, Sudhir K. Jainist [3] conducted totally different analytical models like single strut model, 3-strut model and finite part methodology for RCC framed structures with infill wall and with drawn a conclusion that first methodology was found to be additional economical notwithstanding infill walls area unit out of print within the $\mathrm{G}+1$ floor to supply a automobile parking space

Md. Ferdous Wahid, Md. Nasal Islam [4] dole out unstable associate degreealysis on an empty frame and in crammed frame and located far better results for a frame with infill walls in terms of lateral displacement time and base shear

Knurl Girtin and Kotler David Labors [5] dole out sure comparative study on infilled frames victimisation the strut model to capture the planet wide effects of infills and for this push over analysis was adopted wherever every frame is subjected to totally different loading stages. The result yielded confirmed that result of infill wall reduces the lateral displacement globally

Sayed Mahmoud [6] conducted investigation on unremarkably framed structure with infilled structure wherever totally different models area unit developed to hold out the unstable analysis. The ETABS code was wont to develop totally different models and performing arts the analysis. The results obtained from this investigation showed that there's forceful amendment in dynamic responses obtained from unremarkably framed structure and infilled structure

\section{AIM AND OBJECTIVES OF STUDY}

To study the vibration response of high-rise building frame with infills by equivalent linear static analysis.

To study the tectonic responses of the multi-storey building frame with infill by Non-linear static analysis.

Comparative study of responses thanks to varied loading from the linear and nonlinear analysis. 


\section{METHODOLOGY}

The following methodology was adopted for this study: Modeling of multi-storied building frame is dole out victimisation ETABS. Geometry: set up space and level height area unit thought of.

Material: Beam, Column area unit outlined as concrete and infill as masonry.

Loads: distribution of live masses as per IS: 875: (part 2): 1987 [11] and earthquake masses as per IS 1893: 2002. [10]

Infills area unit sculptured as diagonal strut victimisation equivalent strut methodology.

Linear static and Non-linear static analysis is performed.

The results area unit being compared from totally different responses and tabulated

\section{NUMERICAL STUDY}

In this gift study a high-rise building frame consisting $\mathrm{G}+4, \mathrm{G}+6, \mathrm{G}+9, \mathrm{G}+12, \mathrm{G}+20$ situated in unstable zone-v is taken into account.

The Moment resisting frame is sculptured in ETABS with infills as equivalent diagonal strut. unit as below:

Plan area: $12 \mathrm{~m} \times 12 \mathrm{~m}$

Bay width: $4 \mathrm{~m}$

No. of floors: $\mathrm{G}+4, \mathrm{G}+6, \mathrm{G}+9, \mathrm{G}+12, \mathrm{G}+20$

Floor height: three. $5 \mathrm{~m}$

Grade of concrete: M30

Grade of steel: HYSD 415

Seismic zone: $\mathrm{V}$

Frame type: SMRF

Beam size: $300 \mathrm{~mm} \times 500 \mathrm{~mm}$

Column size: $470 \mathrm{~mm} \times 470 \mathrm{~mm}$

Exterior wall thickness: $230 \mathrm{~mm}$

Interior wall thickness: $115 \mathrm{~mm}$

Slab: $200 \mathrm{~mm}$

Live load: $3 \mathrm{kN} / \mathrm{m}^{2}$

Earthquake load in each direction: IS 1893: 2002 (part 2).

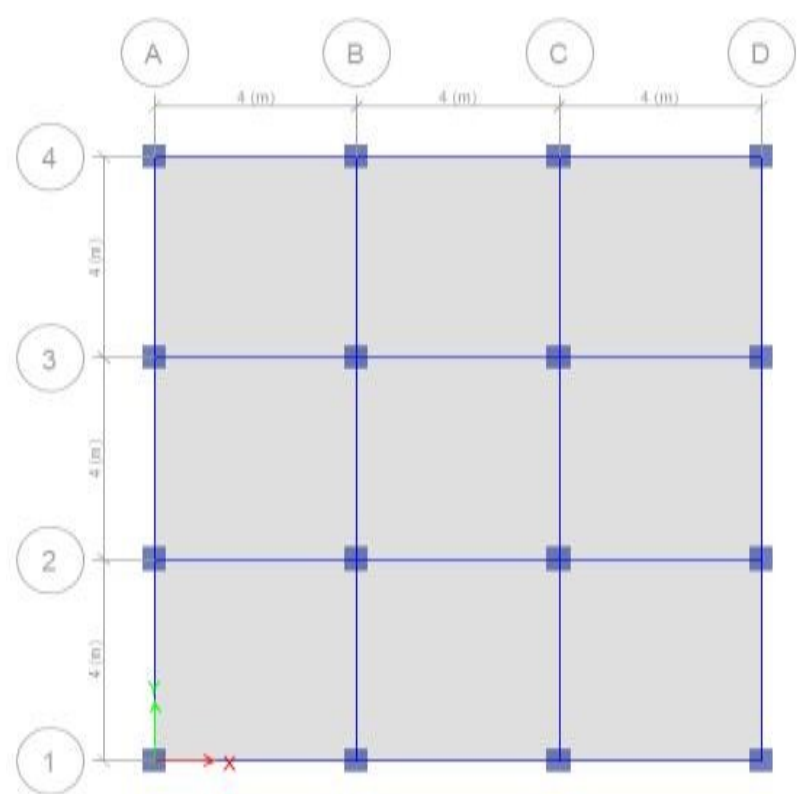

Figure 1: Plan of model generated
The geometric parameters of the model thought of area

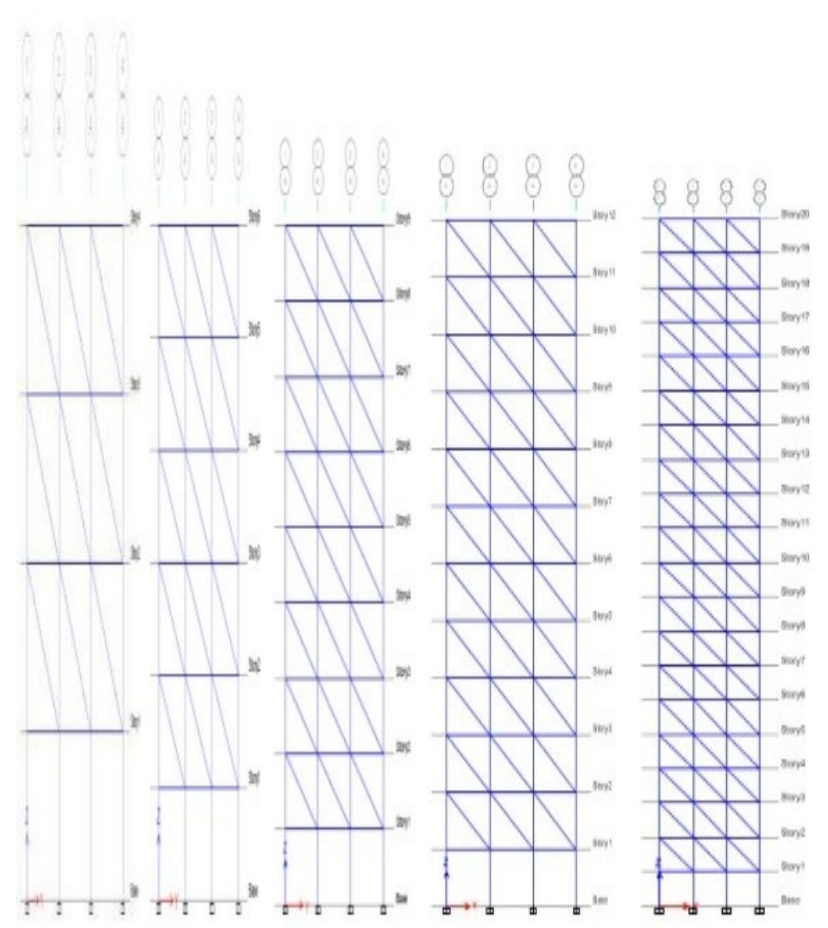

Figure 2: Elevation of the models considered

\section{ANALYSIS}

Equivalent linear static and nonlinear static analysis is performed for the high-rise building frame with infill's. Indian customary code suggests IS 1893:2002 part-1: General provisions and code book [10] for the relevant knowledge to be thought of for the analysis.

Base shear was calculated victimisation the formula: $V_{\mathbf{B}}=$ Ah W

Where $\mathrm{W}=$ unstable weight of building

$\mathrm{Ah}=$ style horizontal unstable constant $=(\mathrm{Z} / 2) \times(\mathrm{I} / \mathrm{R}) \mathrm{x}$ $(\mathrm{Sa} / \mathrm{g})$

$=0.135(\mathrm{G}+4) ; \quad$ zero.135 $(\mathrm{G}+6) ; \quad$ zero.08978 $(\mathrm{G}+9) ;$ zero.067(G+12); zero.0404(G+20)

$\mathrm{Z}=$ Zone issue $=$ zone- $\mathrm{v}=$ zero. $36($ Table -2$)$

$\mathrm{I}=$ Importance issue $=$ one.5 $($ Table 6$)$

$\mathrm{R}=$ Response reduction issue $=$ five $($ Table 7$)$

$\mathrm{Sa} / \mathrm{g}=$ Response acceleration constant (clause.6.4.5)

$\mathrm{T}=(0.09 \mathrm{~h} / \sqrt{\mathrm{d}})=$ zero.363 $(\mathrm{G}+4) ; \quad$ zero. $545(\mathrm{G}+6) ;$ zero.818(G+9); one.091(G+12); one.819(G+20)

Equivalent diagonal strut:

$\mathrm{W}=$ breadth of strut $=$ zero. $.5 \times\left(\sqrt{ } \alpha h^{2}+\alpha l^{2}\right)$

$\mathrm{W}(230 \mathrm{~mm}$ wall $)=$ one. $391 \mathrm{~m} ; \mathrm{W}(115 \mathrm{~mm}$ wall $)=$ one. $654 \mathrm{~m}$

$\alpha \mathrm{h}=(\Pi / 2) \mathrm{x}(4 \mathrm{EfIch} 1 / \mathrm{Emtsin} 2 \theta) 1 / 4$

$\alpha \mathrm{l}=\Pi \mathrm{\Pi}(4 \mathrm{EfIbL} 1 / \mathrm{Emtsin} 2 \theta) 1 / 4$

$\mathrm{Ef}=$ Young's modulus of frame material $=5000 \sqrt{\mathrm{fck}}=$ 27386.128 Mpa Em= young's modulus of masonry = $13800 \mathrm{Mpa}$

Ic $=$ moment of inertia of column

$\mathrm{Ib}=$ moment of inertia of beam

$\mathrm{t}=$ thickness of the outside wall $=230 \mathrm{~mm}$

$\mathrm{t}=$ thickness of the inside wall $=115 \mathrm{~mm}$ 
$=3 \mathrm{~m}$

$\mathrm{L} 1=$ bay breadth $=\mathrm{c} / \mathrm{c}$ distance between columns $=$ three. $53 \mathrm{~m}$

$$
=1 / \tan (\mathrm{h} 1 / \mathrm{L} 1)=40^{\circ} 21^{\prime} 35.37^{\prime \prime}
$$

\section{RESULTS AND DISCUSSIONS}

Multi level building frame with infills, sculptured as equivalent diagonal strut is analyzed for buildings with same level height and totally different no. of stories like $\mathrm{G}+4$, $\mathrm{G}+6, \mathrm{G}+9, \mathrm{G}+12, \mathrm{G}+20$, and results area unit tabulated and mentioned. Responses of the structure like period of time, Base shear, Lateral Displacements area unit compared for each linear and non-linear analysis.

\section{TIME amount}

The amendment within the period of time for the primary 5 approaches area unit thought of for various building heights victimisation linear and nonlinear analysis and therefore the results area unit tabulated below in Table one and area unit mentioned.

We know that height of a structure and period of time area unit directly proportional to every different it is detected that there's no a lot of amendment within the period of time up to $21 \mathrm{~m}$ on conducting linear and non linear analysis however there's decrease in period of time from linear to non linear analysis once the peak modified from $21-70 \mathrm{~m}$ a few proportion of zero.564-2.03\%

\section{Base Shear}

The entire lateral force at the bottom of the structure is taken into account. The values of base shear and proportion variation is taken into account for $\mathrm{G}+4, \mathrm{G}+6, \mathrm{G}+9, \mathrm{G}+12$, $\mathrm{G}+$ twenty stories's victimisation linear and nonlinear analysis and therefore the results area unit tabulated below in table two and area unit mentioned.

From the Table two, we are able to observe that proportion variation for base shear doesn't show any amendment up to assembling height of thirty one. $5 \mathrm{~m}$ victimisation linear and nonlinear analysis. however with a rise in building height to $42 \mathrm{~m}$ the variation is found to be zero. $001 \%$ and on additional increase tall of building to $70 \mathrm{~m}$, the variation is found to be zero. $06 \%$.

\section{Lateral Displacement}

The displacements at totally different level levels are tabulated in Table three and therefore the proportion variation is given.

It is discovered that there's no variation in lateral displacement up to a $21 \mathrm{~m}$ height of building for linear and non-linear analysis however with a rise tall of building the utmost lateral displacement will increase from linear to nonlinear analysis with a variation of zero. $81 \%$ for $31.5 \mathrm{~m}$, $1.38 \%$ for $42 \mathrm{~m}$ and thirteen. $2 \%$ for $70 \mathrm{~m}$.

\section{CONCLUSIONS}

From the on top of approach we have a tendency to might see that for low raised buildings there's no a lot of variation in base shear, lateral displacements, and period of time by performing arts linear and non linear analysis.
In the gift approach there's alittle variation in base shear for the structure having $42 \mathrm{~m}$ height and it will increase additional

From the given set up it is discovered that there's giant variation in displacements in non linear analysis compared with linear analysis and each the ways showed nearly same values up to a height of $21 \mathrm{~m}$,yet, the lateral displacements values raised by zero. $81 \%$ for $31.5 \mathrm{~m}$ and $1.38 \%$ for $42 \mathrm{~m}$ and thirteen. $2 \%$ for $70 \mathrm{~m}$.

It is discovered that the period of time was same up to $21 \mathrm{~m}$ in each the ways however from thirty one. $5 \mathrm{~m}$ height it's discovered that it showed decreasing nature compared to linear analysis

\section{FUTURE SCOPE OF STUDY}

Further study is done by maintaining identical height of the building with varied level heights.

Analysis is performed for buildings having totally different geometric form and result is discovered.

Different ways like Time history analysis can even be performed for structures with infills.

The nonlinear dynamic analysis is dole out to grasp the present behavior of buildings with regular pure mathematics and irregular pure mathematics.

\section{REFERENCE}

1. Wakchaure M.R, Ped S. P on "Earthquake Analysis of High-Rise Building with and Without Infill wall" IJEIT 2, August 2012, Volume 2, Issue 89, PP: 89-94.

2. Hemant B. Kaushik, Durgesh C. Rai, and Sudhir K. Jain on "A Rational approach to analytical modeling of masonry infills in reinforced concrete frame buildings" The 14thWorld Conference on Earthquake Engineering, October 12-17, 2008.

3. P. Reza*, M.F. Wahid and D.M.N. Islam on "Comparative Study of Bare Frame and Infilled Frame Buildings Due To Seismic Load" in 11th Global Engineering, Science and Technology Conference, 18 19 December.

4. Konuralp Girgin and Kutlu Darılmaz on "Seismic Response of Infilled Framed Buildings Using Pushover Analysis" volume 54, number 5, PP: 1-7

5. Sayed Mahmoud, Magdy Genidy. Hesham Tahoon on "Time-History Analysis of RCC Frame Buildings with Soft Storeys" Research gate: Article · December 2016.

6. IS 456: 2000: code for RCS

7. IS 1893(Part 1):2002: proof for Earthquake Resistant Design of Structures. Part 1: general provisions and buildings.

8. IS: 875(part 2): 1987: Code of practice for design loads for buildings and structure 
International Conference on Recents Advancements in Engineering and Technology (ICRAET-18) |15th and 16th

\section{AUTHORS PROFILE}

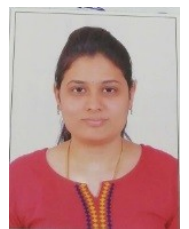

Ms. S. Swapna

M.Tech(SE), AMIE,

Assistant Professor, Department of Civil Engineering,

Siddhartha Institute of Technology and Sciences,

Hyderabad

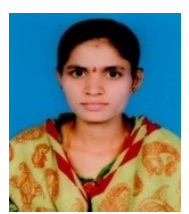

Ms.V.Kavitha

M.Tech(SE),

Assistant Professor, Department of Civil Engineering,

Siddhartha Institute of Technology and Sciences,

Hyderabad.

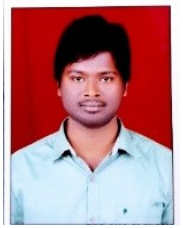

Mr.T.Venkatesh

M.Tech(SE)

Assistant Professor, Department of Civil Engineering,

Siddhartha Institute of Technology and Sciences,

Hyderabad.

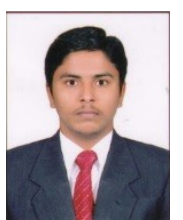

Mr.K.Sanjay Kumar

M.Tech(SE),

Assistant Professor, Department of Civil Engineering,

Siddhartha Institute of Technology and Sciences,

Hyderabad. 